\title{
Variant biochemical responses: intrinsic and adaptive system for ecologically different rice varieties
}

\author{
Shamshad UI Haq ${ }^{1}$. Deepa Kumari ${ }^{1}$ - Prerna Dhingra ${ }^{1}$ - S. L. Kothari ${ }^{2} \cdot$ Sumita Kachhwaha ${ }^{1}$
}

Accepted: 17 September 2020 / Published online: 2 October 2020

(c) Korean Society of Crop Science (KSCS) 2020

\begin{abstract}
India has a diverse range of agro-ecological conditions which support the cultivation of different rice varieties differing in the adaptation which is so important for sustainable development of rice crop. Specific ecotypes of rice adapted to diverse conditions have divergence in their morphology, physiology, biochemistry, molecular function, agronomy, and stress response. In the present study, 12 different rice varieties viz., PB-1, PB-1509, Pusa-RH-10, CSR-30, HKR-47, PR-126, Govind, Sharbati, ADT-37, ADT-39, ADT-45, White Ponni, were selected for the study of intrinsic biochemical behaviour and these varieties belong to different Agro-ecological zones and basmati or non-basmati rice varieties. Amongst intrinsic biochemicals activity, the differential response of radical scavenging, superoxide dismutase (SOD), catalase (CAT) and guaiacol peroxidase (POX) activities, were observed in the selected rice varieties at 14 days old seedling stage, developed under controlled growth conditions. Comparatively, North India region rice varieties displayed an enhanced intrinsic biochemical response than south India region rice varieties. Similarly, basmati rice varieties showed increased biochemical response compared to non-basmati rice varieties. Thus, the differential biochemical responses (radical scavenging, SOD, CAT, and POX activities) observed creates a significant difference between rice varieties and provides valuable information about rice ecotype-biochemical interaction for sustainable adaptive value under different ecological conditions.
\end{abstract}

Keywords Rice $\cdot$ Agro-ecological zone $\cdot$ Basmati or non-basmati $\cdot$ Antioxidant enzyme

\section{Introduction}

India is known to have a diverse range of agro ecological zones for widespread rice cultivation and different types of ecosystems are available for rice farming within the country. Amongst different rice ecosystems, rainfed uplands occupy a major area (37\%) followed by rainfed lowlands (34\%), flood-prone (26\%) and irrigated areas (24\%) (Prasad et al. 2001). Rice cultivation in India also extends from $8^{\circ}$ to $35^{\circ} \mathrm{N}$ latitude and from sea level to as high as $3000 \mathrm{~m}$ with different altitude and climate conditions (https://farme r.gov.in). Accordingly, five major regions are broadly classified within India that are North-Eastern, Eastern, Northern, Western, and Southern Regions which are categorized based

Sumita Kachhwaha

kachhwahasumita@rediffmail.com

1 Department of Botany, University of Rajasthan, Jaipur, Rajasthan 302004, India

2 Institute of Biotechnology, Amity University Rajasthan, Jaipur 302006, India on agro-ecological zone and climatic conditions (Tripathi et al. 2011). Due to diverse ecological conditions, rice farming not only varies greatly on location to location within India but also varies from country to country. Generally, rice crop prefers hot and humid environment while, excessive humidity, extended sunshine and proper water supply are best for rice cultivations. Also, seasons variations are very important factor in India and thus, temperature, soil types, rainfall condition, water availability, intensity of light and moisture content in the atmosphere are most influencing parameters for rice farming.

Rice belongs to Gramineae (Poaceae) family of the Oryza genus which comprises 25 recognized species. Out of 25 species, 23 species belong to wild species while $O$. sativa and $O$. glaberrima are most cultivated or domesticated species. According to nine distinct genome classification (A, $\mathrm{B}, \mathrm{C}, \mathrm{D}, \mathrm{E}, \mathrm{F}, \mathrm{G}, \mathrm{H}$ and $\mathrm{J}$ ) for various rice species, the genus Oryza is grouped into distinct species complexes (Vaughan et al. 2003). The $O$. sativa complex belongs to "A" genome and comprises two domesticated species (O. sativa and $O$. glaberrima) and six wild species (O. rufpogon, O. nivara, 
O. barthii, O. longistaminata, O. meridionalis and O. glumaepatula) (Tripathi et al. 2011; Nadir et al. 2018). Oryza sativa is known as Asian rice and due to its widespread cultivation, two different ecological groups have developed namely; subspecies Indica and subspecies japonica (Oka 1988). Indica rice is preferably cultivated in tropical and subtropical environments at lower latitudes or altitudes, whereas more temperate environments at higher latitudes or altitudes are specified for Japonica rice farming (Yang et al. 2014; Nadir et al. 2018). Under different ecological conditions, both the subspecies of Oryza sativa exhibit great diversification in their morphological, physiological, biochemical, genome sequence, genetic relationship and agronomic traits and also display variation in their yield, quality, and stress-resistant responses (Kawakami et al. 2007; Lu et al. 2009; Hu et al. 2014; Kusano et al. 2015).

Rice crop growth and development under various agroecological conditions shows considerable variation at their morphological, physiological, and molecular levels and these variations are associated with adaptability to a different environmensts and climatic zones (Glaszmann 1987; Oka 1988; Wang et al. 1992). Therefore, ecological, and evolutionary pressures are continuously customizing adaptability in natural populations (Romero 2004; Korte et al. 2005). Moreover, the effect of genotype, environment and mixed performance of genotype and environment interaction influence the phenotypic performance of the species that represent their general and specific adaptability to different environmental conditions (Balakrishnan et al. 2016). Conversely, any influential conditions that transform plant growth performance depends upon the altering of physiological and metabolic processes through changes in the various enzymatic, biochemical, and molecular phenomenon. Importantly, the generation of reactive oxygen species and their counter action by antioxidant enzymes regulate the metabolic and oxidative homeostasis of plant cells (Hussain et al. 2018). Because antioxidant enzyme plays a vital role in regulating physiological and metabolic changes and their differentiating response with their different levels of amount reveals a significant difference between plant species. Moreover, the study of complex environmental pressures on plants provides a specified level of information for analyzing the impact of any constraint during the growth period and improves our understanding of their effect and sustainable development.

In the present study, the 12 distinct rice varieties belonging to a different agro-ecological zones were used to study the variation in their biochemical response during their growth and development at 14 th day old seedlings. The generation of free radical species and their counter action by antioxidant enzymes [superoxide dismutase (SOD), catalase (CAT) and peroxidase (POX)] were examined under controlled conditions amongst 12 different rice varieties. The present study provides information about differences in their intrinsic biochemical response in the selected rice varieties beside of their distinct morphology, physiology, and ecology under normal culture conditions.

\section{Materials and methods}

\section{Plant material collection and culturing}

The different agro-ecological zones based twelve rice varieties namely; PB 1, PB 1509, Pusa RH 10, CSR 30, HKR 47, PR 126, Govind, Sharbati, ADT-37, ADT-39, ADT-45 and White Ponni, were selected for the present study. These varieties belong to different climatic conditions and their farming is very commonly done in north and south regions of India (Table 1). For the experiment, seeds were dehusked manually followed by rinsing several times with distilled water. Surface sterilization was performed with $4 \%$ sodium hypochlorite $(\mathrm{NaClO})$ solution for 20 min followed by 3 times washing with distilled water to remove traces of disinfectant (Haq et al. 2019). Further, the seeds were aseptically surface sterilized with mercuric chloride $(0.1 \% \mathrm{w} / \mathrm{v})$ solution (Merck, India) for 3 min then washed with distilled water for 3-4 times. Sterilized seeds from 12 different varieties were cultured on the water-agar environment for 14 days in triplicates under controlled conditions in the culture chamber.

\section{Free radical scavenging activity}

The methanolic extracts of 14 days old seedlings of 12 rice varieties were used for free radical scavenging activity through diphenyl-picrylhydrazyl (DPPH) assay. The test was performed in a triplicate manner with $0.002 \% \mathrm{DPPH}$ in methanol and $0.250 \mathrm{ml}$ plant extract was used for the analysis in $3 \mathrm{ml}$ reaction volume. After $30 \mathrm{~min}$ incubation at room temperature, the absorbance was recorded at $517 \mathrm{~nm}$ and the blank was set with $0.002 \%$ DPPH methanolic solution (Bemani et al. 2012). The Free radical scavenging potential was measured by the formula:

$\%$ inhibition of DPPH radical $=\left(1-A_{\text {sample }} / A_{\text {blank }}\right) \times 100$.

where, $A_{\text {blank }}$ is the absorbance of the control reaction (containing all reagents except the test sample), and $A_{\text {sample }}$ is the absorbance of the sample/reference.

\section{Enzyme extraction and antioxidant enzyme assay:}

The enzyme extraction was carried out from 14 days old seedling of 12 different rice varieties. The homogenization was executed in ice chilled $50 \mathrm{mM}$ Sodium phosphate buffer (pH 7.0) containing 2 mM EDTA, $5 \mathrm{mM} \beta$-mercaptoethanol 
Table 1 Comparative details of 12 different rice varieties belonging to the distinct agro-ecological zones of India

\begin{tabular}{|c|c|c|c|c|c|}
\hline Serial no. & Variety name & Crop maturation duration & Eco-system & Special characteristics & Cultivation zones \\
\hline 1 & PB-1 & 130-135 days & Irrigated & $\begin{array}{l}\text { Semi-dwarf, high yielding and } \\
\text { basmati rice or scented variety } \\
\text { with soft texture and pleasant } \\
\text { aroma }\end{array}$ & $\begin{array}{l}\text { North India Province: Punjab, } \\
\text { Haryana, Uttar Pradesh, Uttara- } \\
\text { khand }\end{array}$ \\
\hline 2 & PB 1509 & 115-120 days & Irrigated & $\begin{array}{l}\text { Semi-dwarf stature, high yielding } \\
\text { and basmati rice variety }\end{array}$ & $\begin{array}{l}\text { North India Province: Haryana, } \\
\text { Punjab, Delhi, Uttar Pradesh }\end{array}$ \\
\hline 3 & PB-RH-10 & 100-115 days & Irrigated & $\begin{array}{l}\text { Early maturing, high yielding, } \\
\text { fine grain and basmati rice } \\
\text { variety }\end{array}$ & $\begin{array}{l}\text { North India Province: Punjab, } \\
\text { Haryana, Delhi, Uttar Pradesh, } \\
\text { Uttarakhand }\end{array}$ \\
\hline 4 & CSR-30 & 140 days & Irrigated & $\begin{array}{l}\text { Long slender, highly scented } \\
\text { grains and basmati rice variety } \\
\text { with salt tolerant nature }\end{array}$ & $\begin{array}{l}\text { North India Province: Haryana, } \\
\text { Punjab, Uttarakhand, Uttar } \\
\text { Pradesh }\end{array}$ \\
\hline 5 & HKR-47 & 135 days & Irrigated & $\begin{array}{l}\text { Semi dwarf, long slender grain } \\
\text { and non-basmati rice variety }\end{array}$ & $\begin{array}{l}\text { North India Province: Haryana, } \\
\text { Uttar Pradesh }\end{array}$ \\
\hline 6 & PR-126 & 93-125 days & $\begin{array}{l}\text { Irrigated mid- } \\
\text { early rice } \\
\text { ecosystem }\end{array}$ & $\begin{array}{l}\text { Early maturing, non-basmati rice } \\
\text { variety and resistant to several } \\
\text { pathogens }\end{array}$ & North India Province: Punjab \\
\hline 7 & Govind & 95-110 days & Rainfed Early & $\begin{array}{l}\text { Dwarf, long slender grain and } \\
\text { non-basmati rice variety }\end{array}$ & $\begin{array}{l}\text { North India Province: Uttar } \\
\text { Pradesh }\end{array}$ \\
\hline 8 & Sharbati & 125-135 days & Irrigated & $\begin{array}{l}\text { High yielding and semi dwarf } \\
\text { and non-basmati rice variety }\end{array}$ & $\begin{array}{l}\text { North India Province: Punjab, } \\
\text { Haryana, Uttar Pradesh }\end{array}$ \\
\hline 9 & ADT-37 & 105 days & Irrigated Early & $\begin{array}{l}\text { Short duration, semi dwarf, non- } \\
\text { basmati rice variety and resist- } \\
\text { ant to various pathogens }\end{array}$ & $\begin{array}{l}\text { South India Province: Tamil Nadu, } \\
\text { Pondicherry and Andhra Pradesh }\end{array}$ \\
\hline 10 & ADT-39 & 120-125 days & Irrigated Medium & $\begin{array}{l}\text { Early maturing, dwarf, non-bas- } \\
\text { mati rice variety and resistant to } \\
\text { various pathogens }\end{array}$ & $\begin{array}{l}\text { South India Province: Tamil Nadu, } \\
\text { Pondicherry }\end{array}$ \\
\hline 11 & CO-45 & 135 days & Irrigated low land & $\begin{array}{l}\text { Dwarf, long slender grain, non- } \\
\text { basmati rice variety and resist- } \\
\text { ant to various pathogens }\end{array}$ & $\begin{array}{l}\text { South India Province: Tamil Nadu, } \\
\text { Pondicherry }\end{array}$ \\
\hline 12 & White Ponni & 135-140 days & Irrigated & $\begin{array}{l}\text { Tall, non-basmati rice variety and } \\
\text { resistant various pathogens }\end{array}$ & $\begin{array}{l}\text { South India Province: Tamil Nadu, } \\
\text { Andhra Pradesh }\end{array}$ \\
\hline
\end{tabular}

and $4 \%$ PVP-40. Then, the homogenate was centrifuged at $15,000 \mathrm{rpm}$ for $30 \mathrm{~min}$ at $4{ }^{\circ} \mathrm{C}$ and supernatant was collected in separate vials and stored at $-20^{\circ} \mathrm{C}$ till further analysis. The supernatant was used for antioxidants enzyme assay which are as follows:

\section{Superoxide dismutase (SOD, EC 1.15.1.1)}

SOD activity was calculated through the inhibition of photochemical reduction of nitroblue tetrazolium (NBT) by enzyme extract. The reaction mixture of $1 \mathrm{ml}$ comprised $50 \mathrm{mM}$ potassium phosphate buffer ( $\mathrm{pH} 7.8$ ), $2 \mathrm{mM}$ riboflavin, $75 \mathrm{mM}$ NBT, $13 \mathrm{mM}$ DL methionine, $100 \mathrm{mM}$ EDTA and enzyme extract $(50 \mu \mathrm{l})$ (Beauchamp and Fridovich 1971). The reaction was initiated by illuminating for $30 \mathrm{~min}$ at $25{ }^{\circ} \mathrm{C}$ and absorbance was recorded at $560 \mathrm{~nm}$. One unit of activity was determined as the amount of enzyme required to inhibit the photo-reduction of NBT to blue formazan by $50 \%$ and was expressed as SOD units per gm fresh weight (Fw).

\section{Catalase (CAT, 1.11.1.6)}

Catalase activity was measured at $25{ }^{\circ} \mathrm{C}$ through the decrease in absorbance of $\mathrm{H}_{2} \mathrm{O}_{2}$ at $240 \mathrm{~nm}$ for 3 min by the method described by Aebi 1984. The reaction mixture of $1 \mathrm{ml}$ contained $10 \mathrm{mM} \mathrm{H}_{2} \mathrm{O}_{2}$ in $50 \mathrm{mM}$ phosphate buffer ( $\mathrm{pH}$ 7) and $50 \mu 1$ enzyme extract (Aebi 1984). CAT activity was expressed as $\mathrm{U}$ ( $\mu \mathrm{mol}$ of $\mathrm{H}_{2} \mathrm{O}_{2}$ decomposed $\min ^{-1}$ ) per gm Fw using the extinction coefficient $39.4 \mathrm{mM}^{-1} \mathrm{~cm}^{-1}$.

\section{Peroxidase (POX; EC 1.11.1.7)}

Peroxidase or Guaiacol peroxidase activity was determined by the oxidation of guaiacol to a colored tetra-guaiacol at $25{ }^{\circ} \mathrm{C}$ which led to an increase in absorbance and measured through spectrometric analysis. The reaction mixture of $1 \mathrm{ml}$ contained $50 \mathrm{mM}$ phosphate buffer ( $\mathrm{pH} 7), 9 \mathrm{mM}$ guaiacol, $10 \mathrm{mM} \mathrm{H} \mathrm{O}_{2}$ and $50 \mu \mathrm{l}$ of enzyme extract (FernándezGarcía et al. 2004). The increase in absorbance is recorded at $470 \mathrm{~nm}$ for $3 \mathrm{~min}$ at $30 \mathrm{~s} \mathrm{~min} \mathrm{interval} \mathrm{and} \mathrm{blank} \mathrm{was}$ 
without enzyme extract in the reaction mixture. The enzyme activity was expressed as $U$ ( $\mu$ mol of guaiacol oxidized or guaiacol dehydrogenation product (GDHP) $\mathrm{min}^{-1}$ ) per gm $\mathrm{Fw}$ and extinction coefficient of its oxidation product is $26.6 \mathrm{mM}^{-1} \mathrm{~cm}^{-1}(\varepsilon)$.

\section{Statistical analysis}

All the experiments were carried out in triplicates and data are expressed in figures with mean \pm standard deviation followed by one-way ANOVA fulfillment was performed for statistical differences among the means of two or more groups using Microsoft Excel program 2007. Further, the post hoc pairwise comparisons test was performed through the Tukey-Kramer test and $P$ value $<0.05$ was considered as statistically significant. Moreover, the principal component analysis (PCA) was used to identify the covariance structure and relationships of the samples based on the information from the variables. The result from biochemical responses such as DPPH, SOD, CAT and POX of different rice seedlings were utilized for the PCA requirement. Moreover, cluster analysis was achieved using results from biochemical responses (DPPH, SOD, CAT and POX) for better understanding of hierarchical associations, on the basis of unweighted pair group method with arithmetic mean (UPGMA) and Euclidean distance methods. The Tukey-Kramer test, principal component analysis (PCA) and cluster analysis (CA) were performed using PAST statistical software (Hammer et al. 2001).

\section{Result and discussion}

The present study was conducted on twelve different rice varieties belonging to distinct agro-ecological zones and ecotypes which are cultivated specifically in north and south province of India, respectively (Fig. 1). To get an understanding, the 14 day old rice seedlings were developed on

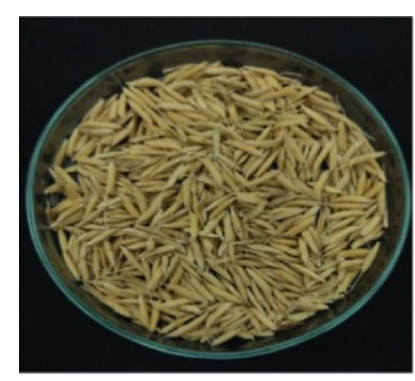

PB-1

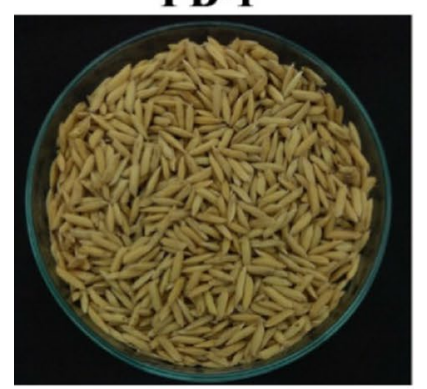

HKR-47

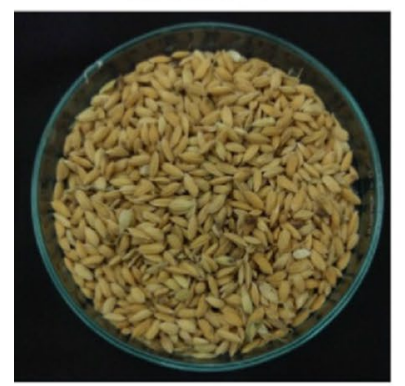

ADT-37

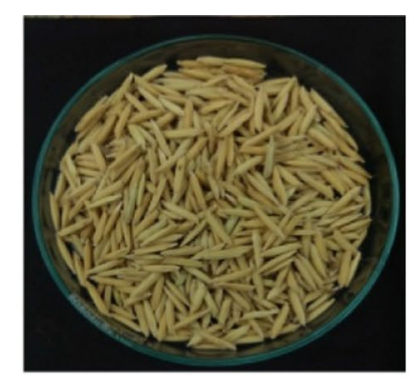

PB-1509

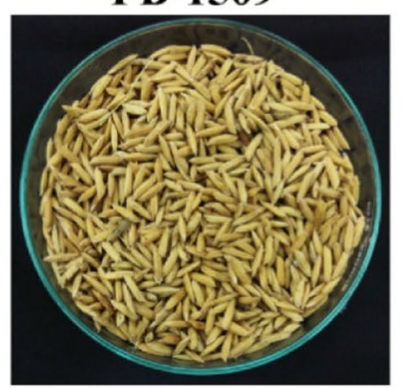

PR-126

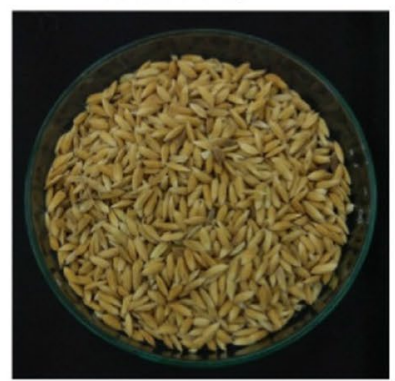

ADT-39

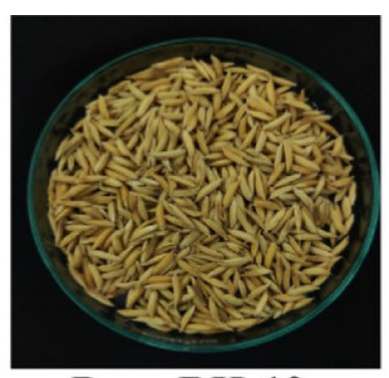

Pusa-RH-10

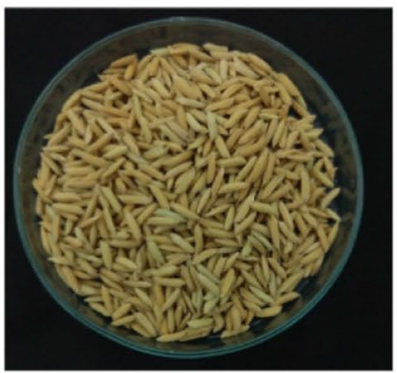

GOVIND

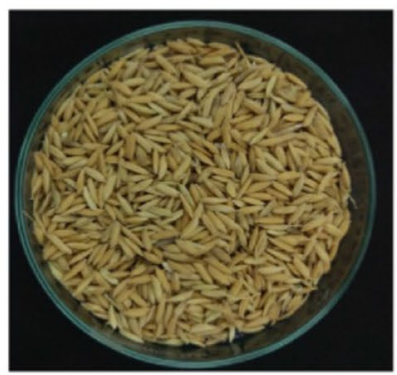

CO-45

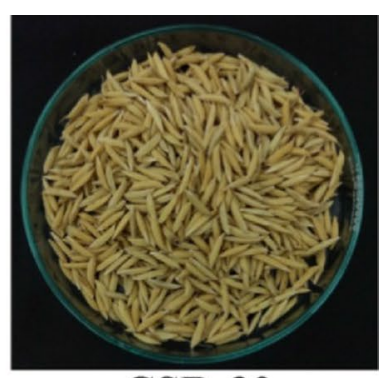

CSR-30

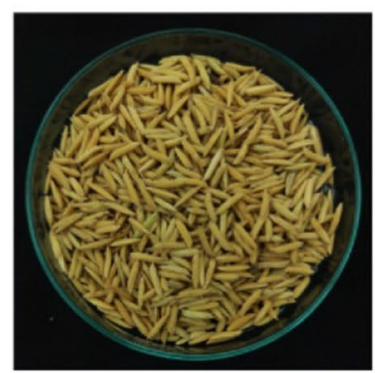

SHARBATI

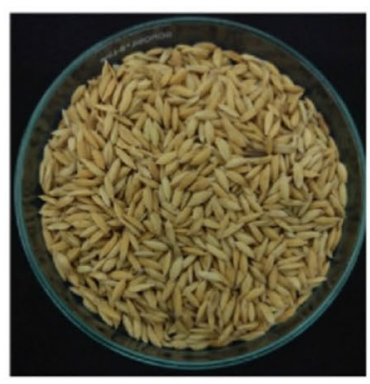

WHITE PONNI

Fig. 1 Twelve different rice varieties used for the studies which represent distinct morphological and physiological characteristics and belong to different ecological zones of India 
water-agar environment under controlled system and were employed for the identification of free radical scavenging capacity and antioxidant enzymes comprising superoxide dismutase (SOD), catalase (CAT), and guaiacol peroxidase (POX). In the present study, the comparative overview is represented not only rice varieties belonging to different agro-ecological conditions but also between basmati and non-basmati rice varieties. The several biochemicals studied here are very important for vital functioning in plant and have an impact directly and indirectly on normal growth and development.

\section{Radical scavenging activity}

The free radical scavenging activity was performed on 14 th days old rice seedlings using DPPH methods. Presently, the methanolic extracts of 12 different rice seedling comprising PB 1, PB 1509, Pusa RH 10, CSR 30, HKR 47, PR126, Sharbati, Govind, ADT-37, ADT-39, ADT-45, and White Ponni, were evaluated for their radical scavenging activity. The average of DPPH radical scavenging activity of rice seedlings was $74.20 \%$ which were ranged from $66.65 \%$ (CSR-30) to $85.39 \%$ (ABT-45) (Fig. 2). This percentage-based radical scavenging analysis is in accordance with earlier studies reported in different plant species and radical scavenging potential were ranged between from 0.19 to $94.51 \%$ (Dudonne et al. 2009; Ghosh et al. 2013; Haq et al. 2019). Additionally, non-basmati varieties displayed increased radical scavenging activity than basmati varieties and India south region varieties showed enhanced radical scavenging potential compared to India north region varieties. For instance, PB 1509 variety showed increased DPPH percent inhibition and lowest was seen in CSR-30 variety amongst basmati varieties and amongst non-basmati varieties, ABT-45 represented enhanced radical scavenging potential while lower was seen in Govind variety. For north region varieties, Sharbati variety showed an enhanced DPPH activity and reduction was observed in Govind variety comparatively. Amongst south region rice varieties, the improved DPPH potential was identified in ABT-45 and reduced DPPH value was found to be noted in ABT-39. Earlier, a similar study has been reported that DPPH were ranged from 13.0 to $76.4 \%$ amongst nine red and three black rice varieties belonging to different geographical condition comprising Thailand, China and Sri Lanka (Sompong et al. 2011).

Presently, we used electron transfer (ET) principlebased DPPH methodology for radical scavenging activity which was determined by calculating the percentage of antioxidant activity through reduction of DPPH into yellow colored diphenyl picryl hydrazine compound using a spectrophotometer (El Bedawey et al. 2010). This change in colour of DPPH can be correlated with the presence of antioxidant molecules in the biological extract that quench DPPH free radicals by providing electron donation and convert them into bleached product resulting of decrease in absorbance at $515-520 \mathrm{~nm}$ (Ribeiro et al. 2006). Commonly, hydrogen atom transfer (HAT) and electron transfer (ET) principle are two common methodologies which are used for identification of in vitro radical scavenging activities in the biological extracts and both methods are responsible for the neutralization of free radicals. Most of HAT-based assays are kinetics based and involve in competitive reaction system in which antioxidant and substrate compete for radicals while ET based methods evaluate the ability of an antioxidant in the reduction method and measure the colour change during reduction (Apak et al. 2007).

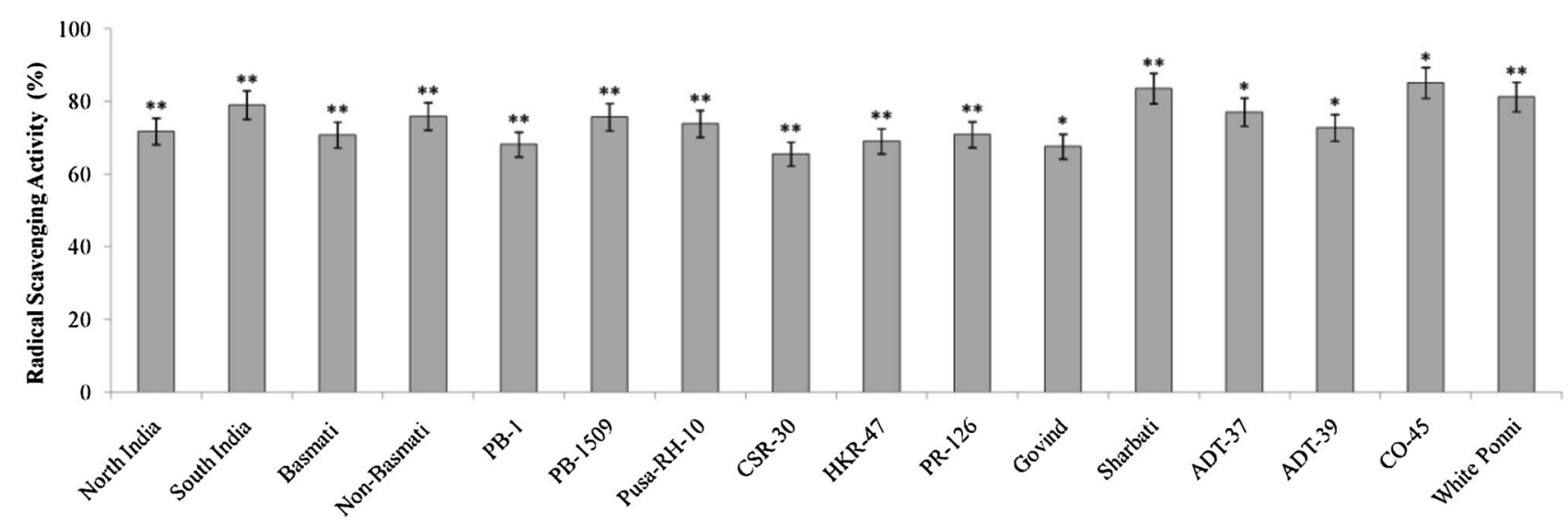

Rice Varieties

Fig. 2 Intrinsic DPPH radical scavenging activity amongst 12 ecologically divergent rice varieties. The data represent as mean $\pm S D$ $(n=3)$ and asterisks $*$ and $* *$ above the mean bar indicate significant and significantly different, respectively, at $P<0.05$ based on the post hoc multiple comparison Tukey-Kramer test 
In the present study, 12 different rice varieties represented a distinct level of their antioxidant capacities through DPPH assay which might be correlated to their different geographical localizations, ecosystem, developmental processes, physiological response, and genetic background. Moreover, this differential nature of antioxidant capacity can also be linked to a diverse range of phenolic compounds in their methanolic extracts because phenolic compounds are known as natural antioxidants in plants (Vichapong et al. 2010; Gonçalves et al. 2017; Huyut et al. 2017). Phenolic compounds are the class of secondary metabolites having a diverse range of chemical structure and function with either in bound or free form in plants. The free forms of phenolic compounds comprise flavonoids or proanthocyanidins while bound forms of phenolic compounds are known as ester linked to cell wall polymers (Bonoli et al. 2004). During germination, it has been observed that rice seeds contain an increased level of $\alpha$-tocopherols (Moongngarm and Saetung 2010), total phenolic (Tian et al. 2004) and anthocyanin contents (Sutharut and Sudarat 2012) which are believed to be potent antioxidants and have free radical quenching capacities (Mittler 2002; Tian et al. 2004; Umnajkitikorn et al. 2013; Huyut et al. 2017). Flavonoid compounds comprising catechin, kaempferol, myricetin and quercetin are seen more commonly in rice (Du et al. 2012). Further, phenolic compounds were found to be as major contributors of variations amongst black rice, red rice and white rice grain extract (Fidrianny et al. 2016). Apart from this, biochemical interactions often generate a diverse range of free radicals which act as necessary intermediates for a variety of cell signaling and biological process under controlled way but an excess of their productions wreak havoc or oxidative damage to the biological cell (Mittler 2017; Haq et al. 2019). Amongst different types of free radicals, oxygen-derived radicals are most concerned widely and collectively known as reactive oxygen species (ROS) which is formed by sequential reduction of molecular oxygen to the formation of a group of ROSs. Recently, several studies have been documented the involvement of ROSs in signaling reactions, cellular proliferation and differentiation, biotic and abiotic stresses, seed germination, root/shoot development and flowering process etc. (Tsukagoshi 2016; Du and Scheres 2018; Mhamdi and Breusegem 2018).

\section{Antioxidant enzyme activity}

In the present study, the baseline for antioxidant enzymes was measured amongst 12 different rice varieties at 14 day old rice seedlings which were cultured on water-agar environment under controlled system. The antioxidant enzymes confined to superoxide dismutase (SOD), catalase (CAT) and guaiacol peroxidase (POX) were examined because these enzymes play a fundamental role in the normal progression and defense machinery in the plants. During normal growth and metabolism, the limited amounts of reactive oxygen species (ROSs) are generated in different plant cellular organelles like chloroplast, mitochondria, and peroxisomes. The ROS level in the cells not only act as a secondary messenger but also get regulated by antioxidant defense machinery. Therefore, both ROSs and antioxidant system are required as an essential component for normal growth and cellular homeostasis in the organism (Das and Roychoudhury 2014).

\section{Superoxide dismutase (SOD)}

The distribution of SOD activity was identified amongst 12 different rice varieties belonging to different geographical locations and climatic conditions. Presently, the SOD activity was varied from 180.68 to $228.20 \mathrm{U} / \mathrm{g}$ FW with an average of $207.63 \mathrm{U} / \mathrm{g} \mathrm{FW}$. The deviation in SOD activity was observed which create separation in the action of SOD enzyme into 12 rice seedlings during their normal growth and development. SOD results of present study are in the accordance with earlier studies (Cavalcanti et al. 2004; Wang et al. 2018). SOD is most important primary enzymatic agent that transforms the superoxide into peroxide through dismutation of 2 molecule of superoxide $\left(\mathrm{O}_{2}{ }^{-}\right)$ into hydrogen peroxide $\left(\mathrm{H}_{2} \mathrm{O}_{2}\right)$ and molecular oxygen $\left(\mathrm{O}_{2}\right)$. Further, the level of peroxide $\left(\mathrm{H}_{2} \mathrm{O}_{2}\right)$ is regulated by other antioxidant enzymes (CAT, APX, GPX, POX) accordingly while a certain level of $\mathrm{H}_{2} \mathrm{O}_{2}$ concentration is maintained within the cells for signaling purpose which is responsible for regular physiological and biochemical processes in plants (Niu and Liao 2016). SOD is identified as first-line defense machinery in all the aerobic organisms and play an important role in protecting from the harmful effect of ROS which is overwhelmingly generated under various situation including environmental adversity, diseases, pathogenic infection, biotic and abiotic stress and oxidative damage etc. (Hasanuzzaman et al. 2013; Caverzan et al. 2016; Xie et al. 2019).

Moreover, Basmati rice varieties showed comparatively increased SOD activity than non-basmati rice varieties but within Basmati, PB RH 10 and PB-1 varieties represented the highest and lowest SOD activity, respectively. Amongst non-basmati rice varieties, HKR-47 displayed increased SOD level while lowest SOD activity was seen in ABT-45. According to geographical distribution, it seems that India north region rice varieties displayed more SOD activity compared to India south region rice varieties (Fig. 3). The deviation in the distribution of SOD activity was observed within and across selected rice varieties and distinct ecological groups, respectively. The variation in the minimum threshold value amongst rice varieties might be due to different demographic, geographic, climatic condition, and genetic adaptation. Further, the deviation in SOD values can 


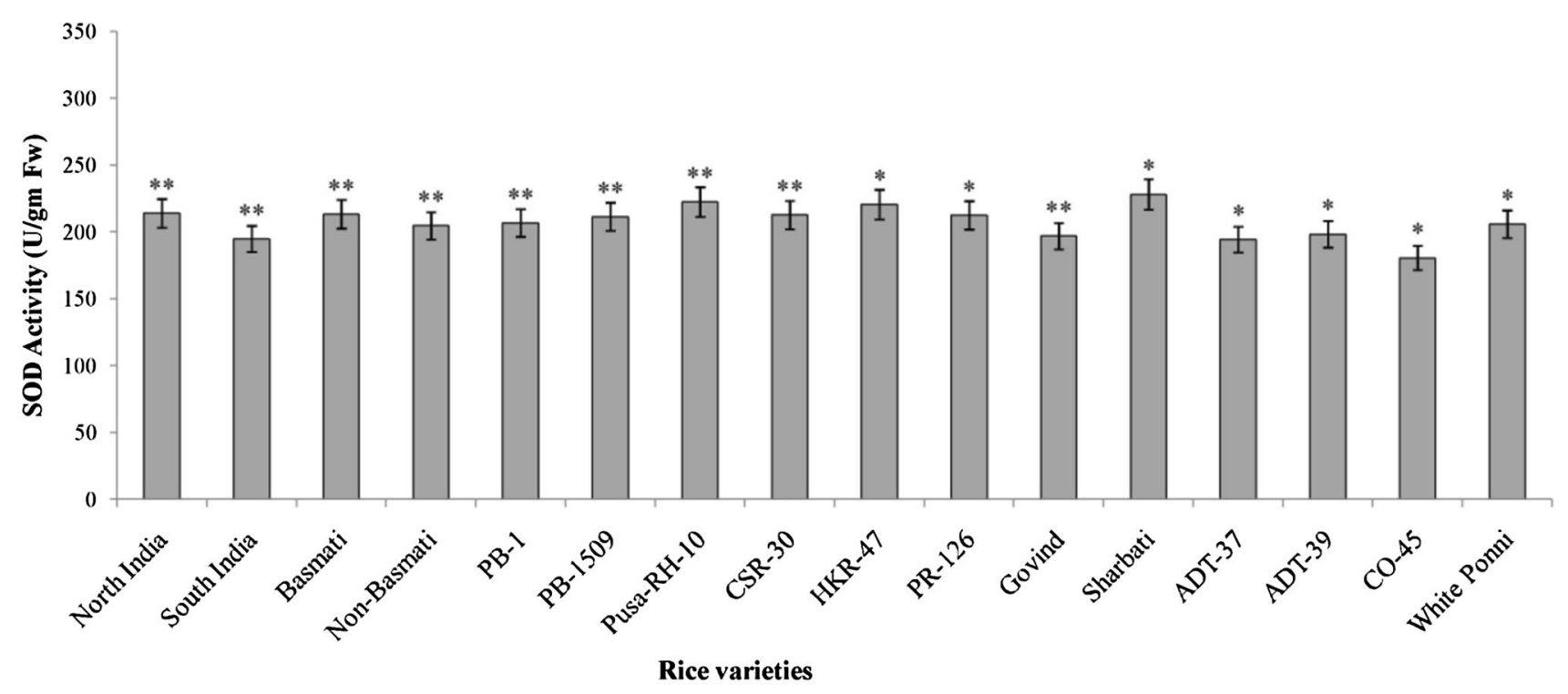

Fig. 3 Intrinsic superoxide dismutase (SOD) activity amongst 12 ecologically divergent rice varieties. The data represent as mean $\pm S D$ $(n=3)$ and asterisks $*$ and $* *$ above the mean bar indicate significant

also be implicated by different morphological, physiological, biochemical, and molecular makeup which are differentially required for a constant level of growth and development amongst different rice cultivars (Hasanuzzaman et al. 2013; Xie et al. 2019). Additionally, metal cofactor categorized SOD into three different isoforms like, $\mathrm{Cu} / \mathrm{Zn}-\mathrm{SOD}, \mathrm{Fe}-$ SOD and Mn-SOD which are separately localized in different subcellular compartments (Del Rio et al. 1998) and their activities occur distinctively for combating different conditions for survival and maintenance of plant growth. Therefore, all these SOD isoforms have been also identified differentially in various rice seedlings and deviation in SOD activity is also correlated with differential distribution of SOD isoforms (Sharma and Dubey 2005; Sharma et al. 2013; Kaur et al. 2016). In the present study, the deviation in the SOD activity might also be extrapolated with variation in the ecology involved amongst different rice varieties such as soil salt conditions, $\mathrm{pH}$, waterlogging, lightening, temperature, and atmospheric pressure (Gill and Tuteja 2010; Das et al. 2013; Zhang et al. 2015; Kaur et al. 2016; Rossatto et al. 2017; Abdelaziz et al. 2018; Xie et al. 2019).

\section{Catalase (CAT) Activity}

Catalase (CAT) activity was estimated for the selected rice varieties belonging to diverse ecological conditions. A tetrameric heme-containing CAT enzyme plays a key role in dismutation of $\mathrm{H}_{2} \mathrm{O}_{2}$ into $\mathrm{H}_{2} \mathrm{O}$ and $\mathrm{O}_{2}$ after SOD action within all living tissues. It is a unique antioxidant enzyme having very high turnover rate $\left(6 \times 10^{6}\right.$ molecules of $\mathrm{H}_{2} \mathrm{O}_{2}$ to $\mathrm{H}_{2} \mathrm{O}$ and significantly different, respectively, at $P<0.05$ based on the post hoc multiple comparison Tukey-Kramer test

and $\mathrm{O}_{2} \min ^{-1}$ ) and reveal more affinity for $\mathrm{H}_{2} \mathrm{O}_{2}$ but lesser specificity for organic peroxides (Mittler 2002). An average CAT activity was found to be $18.04 \mathrm{U} / \mathrm{g} \mathrm{FW}$ which were ranged from 11.33 (Sharbati) to 29.51 (PB-1) U/g FW. Presently, the action of CAT enzyme amongst the selected rice varieties are in compliance with earlier reports in different rice cultivars (Huang and Guo 2005; Jha and Subramanian 2013). Peroxisomes, a membrane-bound cytoplasmic organelle present in most eukaryotic cells and are believed as a major source for $\mathrm{H}_{2} \mathrm{O}_{2}$ productions by metabolic reactions like $\beta$-oxidation of fatty acids, photorespiration, and purine catabolism (Mittler 2002; Schrader and Fahimi 2006). This generated $\mathrm{H}_{2} \mathrm{O}_{2}$ is promptly degraded by peroxisomally CAT enzyme which help to oxidative balance within the cell (Walton and Pizzitelli 2012) nevertheless other subcellular compartment (cytosol, chloroplast and the mitochondria) are also found to have a role in oxidative balance within the cells through significant CAT activities (Mhamdi et al. 2010). Notably, the low concentration of $\mathrm{H}_{2} \mathrm{O}_{2}$ have tendency to normalize cellular functions like signal transduction, cell proliferation, cell death, redox-balancing, gene expression modulations and other processes but an extensive increased level of $\mathrm{H}_{2} \mathrm{O}_{2}$ leads to have deleterious effect on metabolic dysfunction, affecting normal cellular functions and gigantic damage to biomolecules (DNA, lipids and proteins) (Petrov and Breusegem 2012; Hossain et al. 2015; Niu and Liao 2016).

In the current study, basmati rice varieties exhibited increased CAT activity compared to non-basmati rice varieties. Among basmati varieties, PB-1 revealed the highest 
CAT value and lowest was seen in CSR-30 variety. Amongst non-basmati varieties, PR-126 rice variety showed exceptionally high CAT activity and lowest CAT value was seen in Sharbati rice variety (Fig. 4). Depending upon the geographical distribution of rice varieties, the enhanced CAT activities found to be seen within North India region rice varieties compared to south India region rice varieties in the present study. Because of these results, it can be assumed that the growth and progression of species belonging to different genetic constitution experience certain kind of pressures which are essentially required for normal growth and development. Therefore, behavioral constraint amongst species represents their uniqueness, adaptively to given environment and also creates a separation amongst species. Furthermore, this deviated CAT activity might be correlated with catalase isoenzymes (CAT 1, CAT 2 and CAT 3) which have been identified in higher plants and their differential distribution was noticed in the distinct compartment of the cell amongst angiosperms (Das and Roychoudhury 2014). It has been also documented that CAT activities can be affected by distinct factors such as environmental signal (ozone, temperature, UV irradiation, and $\mathrm{SO}_{2}$ ), exogenous constraint, temporally and spatially regulation of CAT genes, differentially expression of CAT gene and hydrogen peroxide signaling (Scandalios 2005; Kwon et al. 2007; Hossain et al. 2015; Hu et al. 2016).

\section{Peroxidase (POX) activity}

Similarly, guaiacol peroxidase activity was examined in the selected rice varieties at the 14 days old seedling stage. The
POX activity ranged from 5.72 (Govind) to 14.54 (Pusa RH 10) $\mathrm{U} / \mathrm{g}$ FW with an average of $8.97 \mathrm{U} / \mathrm{g}$ FW. In the present study, the guaiacol peroxidase activity is in accordance with previous studies reported in different rice varieties which also reported that POX activity continuously increase during day to day growth in normal as well as in stressed condition but comparatively increased POX activity is observed under stressed condition than normal condition (Sharma and Dubey 2007; Lotfi et al. 2009; Singh et al. 2012; Poli et al. 2018). Guaiacol POX belongs to heme-containing enzyme family composed of 40-50 kDa monomers and ubiquitously present in fungi, plants, and vertebrates. This enzyme is considered as an active representative during normal metabolism as well as defense mechanism against biotic and abiotic stresses (Ghamsari et al. 2007) hence, it is known as stress enzyme (Sharma et al. 2012). It preferably oxidizes aromatic electron donors such as guaiacol and pyragallol by utilization of $\mathrm{H}_{2} \mathrm{O}_{2}$ (Asada 1999). The several kinds of POX enzymes are found in a different compartment of cell [intra cellular (cytosol, vacuole), extracellular (apoplast) and cell wall] and numerous physiological functions are also assigned to plant peroxidases, for example, lignification, suberization, cross linking of cell wall proteins, stress response, defense against pathogens, salt tolerance and senescence (Hiraga et al. 2001; Ghamsari et al. 2007; Gill and Tuteja 2010; Hamann 2012; Pandey et al. 2017; Wu et al. 2019).

Significantly, non-basmati rice seedlings showed reduced POX activity compared to basmati rice seedlings and amongst basmati varieties, the Pusa RH 10 cultivar revealed maximum POX activity but the minimum was found in PB-1 variety. Similarly, the top-notch POX

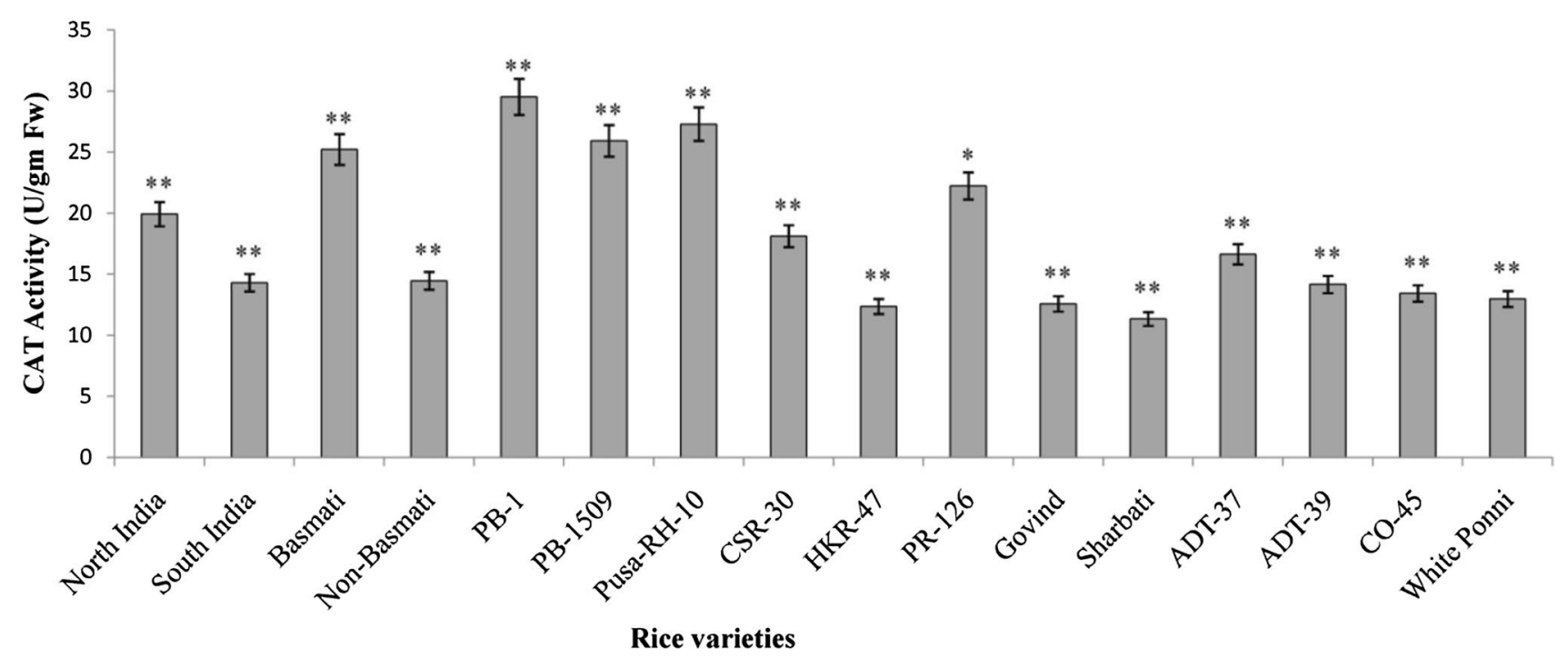

Fig. 4 Intrinsic catalase (CAT) activity amongst ecologically divergent rice varieties. The data represent as mean $\pm \operatorname{SD}(n=3)$ and asterisks * and ** above the mean bar indicate significant and significantly different, respectively, at $P<0.05$ based on the post hoc multiple comparison Tukey-Kramer test 
activity found to be observed in PR 126 but Govind variety displayed a lowest POX value amongst non-basmati cultivars (Fig. 5). According to geographic condition, south India region rice cultivars displayed enhanced POX activity compared to north India region rice cultivars. In the present study, lower POX enzyme activity was observed than CAT activity amongst 12 different rice seedlings but deviation within POX activities was also identified in different rice seedlings belonging to distinct ecology. The discrepancies within POX values is characterized by species-specific condition of POX enzyme, nature of constraint and transform developmental response amongst cultivars during growth and development. The low level of POX activity might be also correlated to normal growth progression under no stress and minimum level of oxidation of phenolic compounds are also responsible for POX action (Taggar et al. 2012). Accordingly, a large set of POX enzyme family are present in higher plants (Welinder 1992) and their expression pattern are differentially orientated, organ specific and developmentally regulated (Klotz et al. 1998; Hiraga et al. 2000). The diversification in the POX function is explained not only by the presence of several isoforms of POX enzyme which results from gene duplication actions during evolution but also depends on the developmental process for organs buildup in distinct sections of plants which explicates an existence and diversification of POX enzymes (Ghamsari et al. 2007; Passardi et al. 2004). Therefore, variation in the Guaiacol POX activities have been confirmed in the previous studies and this change depends upon plant species, stresses and various environmental conditions (Yamane et al. 2009;
Gill and Tuteja 2010; Panda et al. 2019; Sarkar et al. 2013; Banerjee and Roychoudhury 2019; Sharma et al. 2020).

\section{Principal component analysis (PCA) and clustering analysis}

The principle component analysis (PCA) was carried out to examine relationship amongst different rice varieties using data from DPPH, SOD, CAT and POX activities in shoots, based on covariance matrix at 14 days old seedling stage. Under the multivariate statistical methods, PCA a popular statistical procedure which is used for data exploration with reduced data dimensionality, representation of the information in data of high dimension and finding relevance between objects (Çam et al. 2009; Wang and $\mathrm{Hu}$ 2011). Presently, the outcome of PCA was obtained in several principle components (PCs) and loading of PC1 and PC2 accounted for $72.09 \%$ of total variance whereas, PC 1 revealed high eigenvalue of 2.4 with $48.25 \%$ of total variance and PC 2 showed 1.2 eigenvalue with $23.84 \%$ of total variance, respectively (Fig. 6). The results of loading plot of PC1 and PC2 are shown in Fig. 7 and PC1 mostly showed a harmony amongst basmati rice varieties while $\mathrm{PC} 2$ showed positive relationship amongst non-basmati rice varieties. A degree of differentiation was found in basmati and non-basmati rice varieties belonging to diverse ecological nature. Therefore, the present study represented relationship amongst ecologically different rice varieties on the basis of their biochemical (DPPH, SOD, CAT, and POX) responses at 14 days seedling stage. Earlier, the several studies have shown high dimensionality data exploration for number of

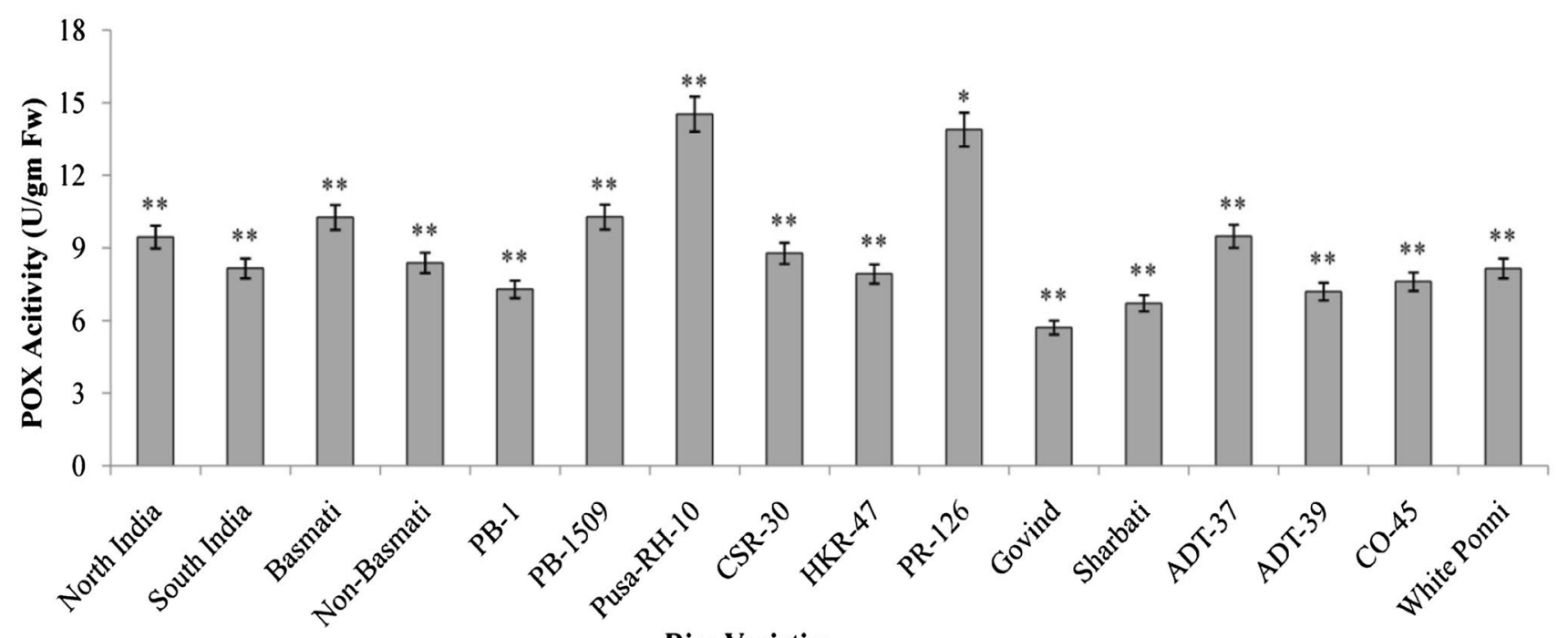

Rice Varieties

Fig. 5 Intrinsic peroxidase (POX) activity amongst ecologically divergent rice varieties. The data represent as mean $\pm \mathrm{SD}(n=3)$ and asterisks $*$ and $* *$ above the mean bar indicate significant and signifi- cantly different, respectively, at $P<0.05$ based on the post hoc multiple comparison Tukey-Kramer test 
Fig. 6 Detail of eigenvalues of each principal component variation that stand for the amount of
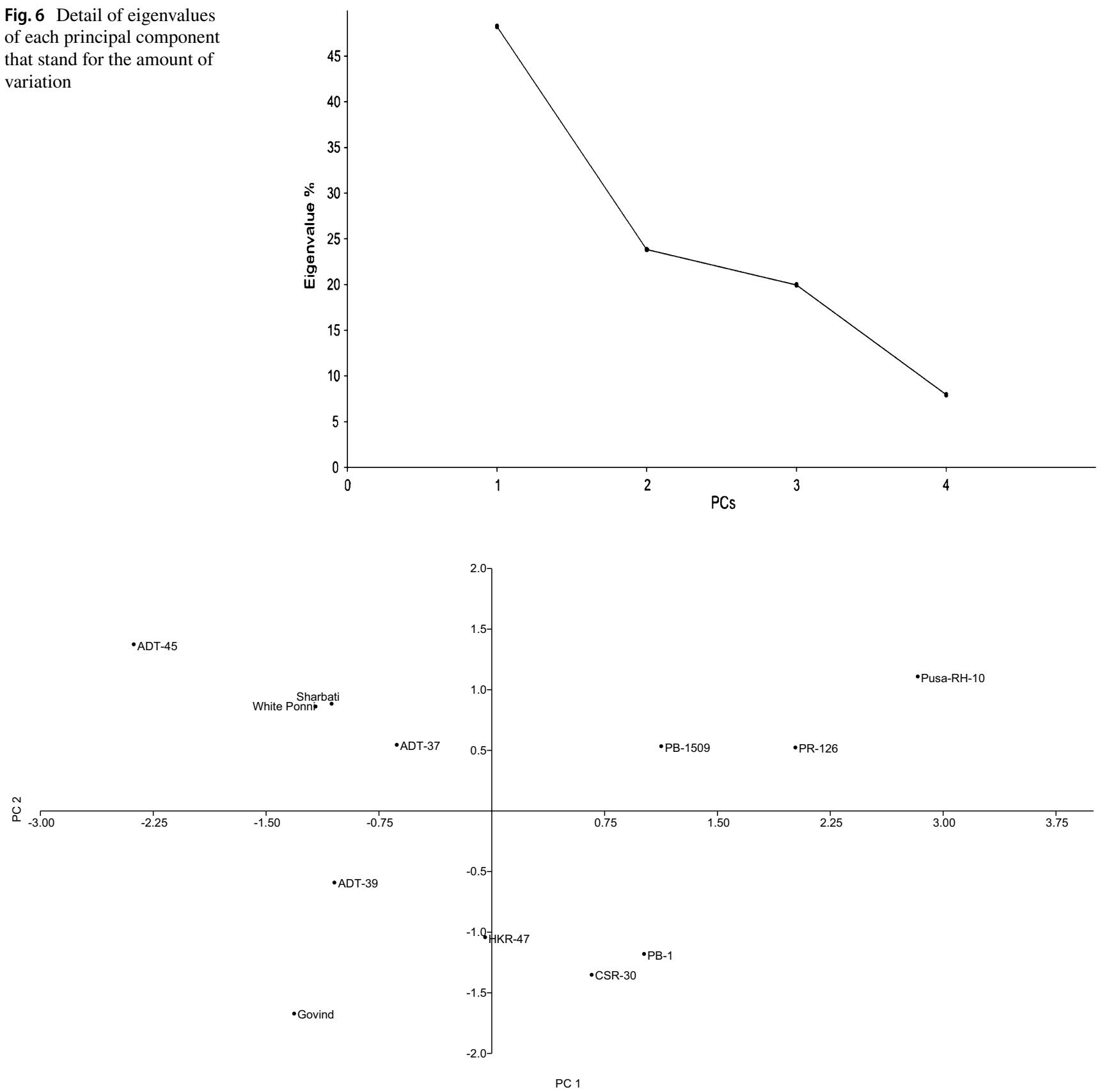

Fig. 7 Biplot obtained from PC 1 and PC 2 showing the relationship amongst 12 ecologically different rice cultivars based on the result from DPPH, SOD, CAT and POX activities in a shoot at 14th days old seedling stage

different variables used and their relationship between the variables using principle component analysis amongst different plant species (Çam et al. 2009; Wong et al. 2006; Boeing et al. 2014). Additionally, cluster analysis was performed amongst 12 different rice varieties on the basis of association amongst DPPH, SOD, CAT, and POX activities in the shoot at 14 days old seedling stage through unweighted pair group method with arithmetic mean (UPGMA) and Euclidean distance methods. Broadly speaking, two major groups were observed from the cluster analysis and somewhat, these groups revealed partition between basmati and non-basmati rice varieties. While group I was mostly concentrated with non-basmati rice varieties including India's North and South region rice varieties except CSR-30 and group II showed a major association of basmati rice varieties except PR-126 (Fig. 8). Thus, cluster analysis represented a resemblance and divergence amongst ecologically different rice varieties and grouped these varieties according to their basmati and 
Fig. 8 UPGMA and Euclidean distance-based cluster analysis showing hierarchical association amongst 12 ecologically different rice varieties using data from biochemical response (DPPH, SOD, CAT and POX) in shoot at 14th days old seedling stage

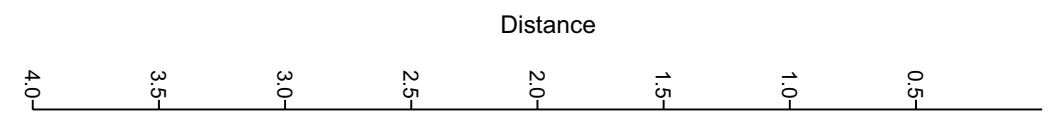

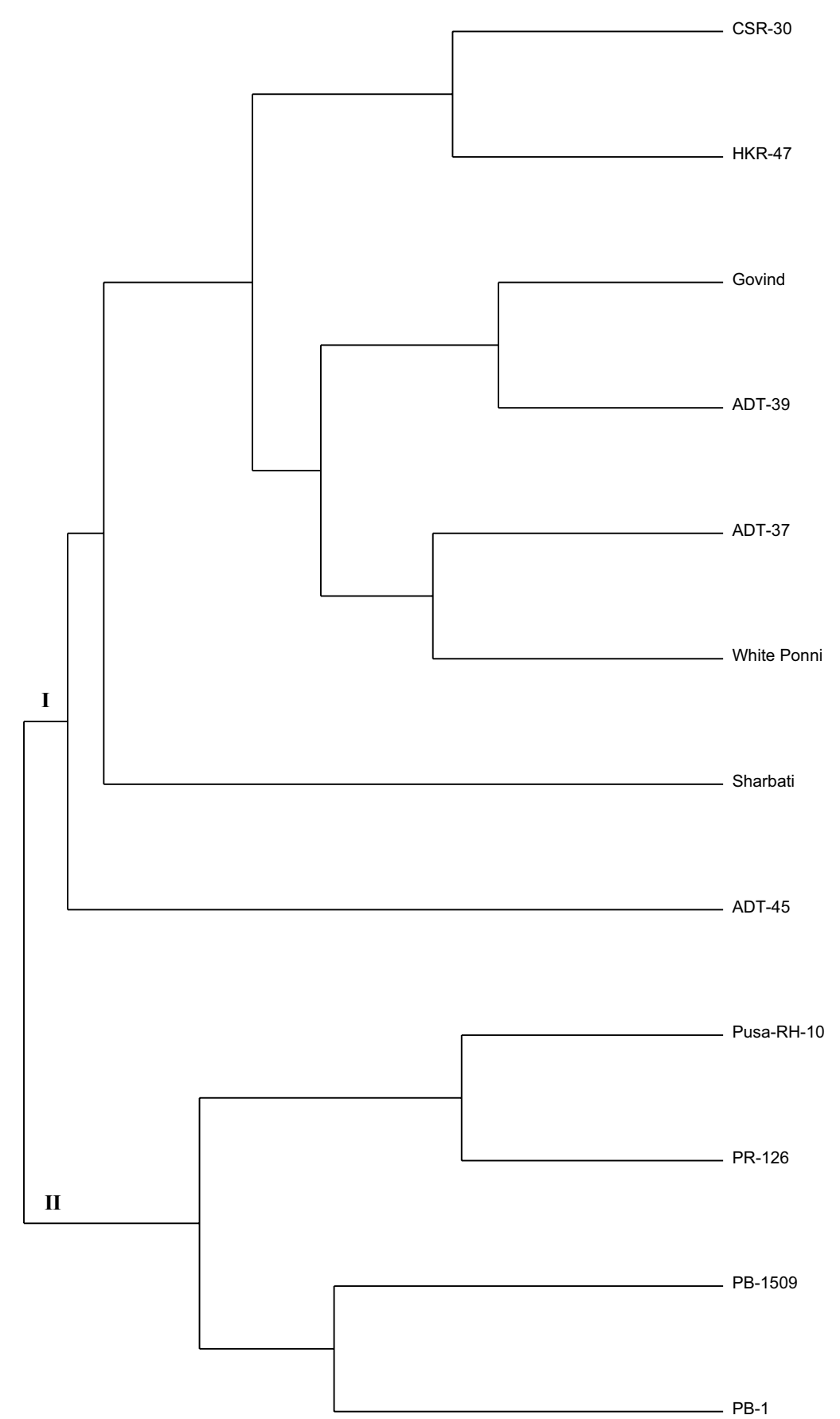

non-basmati nature within distinct edges, respectively, using biochemical responses.

In conclusion, aerobic organisms are exhibited into distinct groups on the basis of their morphological characteristics, physiological processes, molecular functions, evolution pattern and their ecology. These differences create an imposition on the living organism to adapt with the environment and to produce the varied level of reactive oxygen species (ROS) which are essentially required for normal metabolism, signaling and physiological functions but high concentration exacerbate the toxicity of ROS which result in an oxidative burst. Because, ROS are highly reactive 
molecules of oxygen and can have a vital impact on cell damaging not only by altering biomolecules entities such as lipids, proteins, carbohydrates, and nucleic acids but also by disturbing their functions. Significantly, aerobic organisms have well organized antioxidant systems including both enzymatic and non-enzymatic antioxidant arrangements that usually participate in controlling or blocking harmful effects of ROS. In the present study, 12 different rice varieties were used for intrinsic radical scavenging activity and antioxidant enzymes (SOD, CAT and POX) distribution at 14 days old seedling stage which were developed on wateragar system under controlled environment. Consequently, varied levels of radical scavenging potential and antioxidant enzyme functions were observed amongst 12 rice varieties belonging to different morphological, geographical distribution and ecotypes. Hence, a distinct level of ROS and their antioxidant enzyme nature exhibits remarkable differentiation amongst various rice varieties and unveil their sustainable development adaptability according to a different environment, geographical localization, ecotypes, and genetic differences.

Acknowledgements Authors are highly thankful to Council of Scientific and Industrial Research (CSIR) for CSIR-RA fellowship. Authors also acknowledge the Department of Science and Technology (DST) State of Rajasthan for research assistance and UGC-DRS phase II. Department of Botany, University of Rajasthan is also acknowledged for providing necessary facilities.

\section{Compliance with ethical standards}

Conflict of interest The authors declare that there is no conflict of interest regarding the publication of this paper.

\section{References}

Abdelaziz MN, Xuan TD, Mekawy AMM, Wang H, Khanh TD (2018) Relationship of salinity tolerance to $\mathrm{Na}+$ exclusion, proline accumulation, and antioxidant enzyme activity in rice seedlings. Agriculture 8(11): 166

Aebi H (1984) Catalase in vitro. Methods Enzymol 105:121-126

Apak R, Güçlü K, Demirata B, Özyürek M, Çelik SE, Bektaşoğlu B, Berker KI, Özyurt D (2007) Comparative evaluation of various total antioxidant capacity assays applied to phenolic compounds with the CUPRAC assay. Molecules 12(7):1496-1547

Asada K (1999) The water-water cycle in chloroplasts: scavenging of active oxygens and dissipation of excess photons. Annu Rev Plant Biol 50(1):601-639

Balakrishnan D, Subrahmanyam D, Badri J, Raju AK, Rao YV, Beerelli K, Mesapogu S, Surapaneni M, Ponnuswamy R, Padmavathi G, Babu VR (2016) Genotypex environment interactions of yield traits in backcross introgression lines derived from Oryza sativa cv. Swarna/Oryza nivara. Front Plant Sci 7:1530

Banerjee A, Roychoudhury A (2019) Differential regulation of defence pathways in aromatic and non-aromatic indica rice cultivars towards fluoride toxicity. Plant Cell Rep 38(10):1217-1233
Beauchamp C, Fridovich I (1971) Superoxide dismutase: improved assays and an assay applicable to acrylamide gels. Anal Biochem 44(1):276-287

Bemani E, Ghanati F, Boroujeni LY, Khatami F (2012) Antioxidant activity, total phenolics and taxol contents response of hazel (Corylus avellana L.) cells to benzoic acid and cinnamic acid. Not Bot Horti Agrobot Cluj Napoca 40(1):69-73

Boeing JS, Barizão ÉO, e Silva BC, Montanher PF, de Cinque Almeida V, Visentainer JV. (2014) Evaluation of solvent effect on the extraction of phenolic compounds and antioxidant capacities from the berries: application of principal component analysis. Chem Cent J 8(1):48

Bonoli M, Marconi E, Caboni MF (2004) Free and bound phenolic compounds in barley (Hordeum vulgare L.) flours: evaluation of the extraction capability of different solvent mixtures and pressurized liquid methods by micellar electrokinetic chromatography and spectrophotometry. J Chromatogr 1057(1-2):1-12

Çam M, Hışıl Y, Durmaz G (2009) Classification of eight pomegranate juices based on antioxidant capacity measured by four methods. Food Chem 112(3):721-726

Cavalcanti FR, Oliveira JTA, Martins-Miranda AS, Viégas RA, Silveira JAG (2004) Superoxide dismutase, catalase and peroxidase activities do not confer protection against oxidative damage in salt-stressed cowpea leaves. New Phytol 163(3):563-571

Caverzan A, Casassola A, Brammer SP (2016) Reactive oxygen species and antioxidant enzymes involved in plant tolerance to stress. In: Shanker AK, Shanker C (eds) Abiotic and biotic stress in plantsrecent advances and future perspectives. InTech, New York, pp 463-480

Das K, Roychoudhury A (2014) Reactive oxygen species (ROS) and response of antioxidants as ROS-scavengers during environmental stress in plants. Front Env Sci 2:53

Das S, Krishnan P, Nayak M, Ramakrishnan B (2013) Changes in antioxidant isozymes as a biomarker for characterizing high temperature stress tolerance in rice (Oryza sativa L.) spikelets. Exp Agric 49(1):53-73

Del Rio LA, Pastori GM, Palma JM, Sandalio LM, Sevilla F, Corpas FJ, Jiménez A, López-Huertas E, Hernández JA (1998) The activated oxygen role of peroxisomes in senescence. Plant Physiol 116(4):1195-1200

Du Y, Scheres B (2018) Lateral root formation and the multiple roles of auxin. J Exp Bot 69(2):155-167

Du J, Yang T, Zeng YW, Pu XY, Yang SM, Chen XY, Jia P (2012) Determination of flavonoid in rice grain by HPLC. J Plant Genet Res 5:33

Dudonne S, Vitrac X, Coutiere P, Woillez M, Mérillon J-M (2009) Comparative study of antioxidant properties and total phenolic content of 30 plant extracts of industrial interest using DPPH, ABTS, FRAP, SOD, and ORAC assays. J Agric Food Chem 57(5): 1768-1774

El Bedawey A, Mansour E, Zaky M, Hassan AA (2010) Characteristics of antioxidant isolated from some plant sources. Food Sci Nutr $1(01): 5$

Fernández-García N, Carvajal M, Olmos E (2004) Graft union formation in tomato plants: peroxidase and catalase involvement. Ann Bot 93(1):53-60

Fidrianny I, Puspitaningrum DA, Ruslan K (2016) Antioxidant capacities of various grains extracts of three kinds of rice grown in Central Java-Indonesia. Int J Pharmacogn Phytochem Res 8(6):997-1002

Ghamsari L, Keyhani E, Golkhou S (2007) Kinetics properties of guaiacol peroxidase activity in Crocus sativus L. corm during rooting. Iran Biomed J 11:137-146

Ghosh S, Derle A, Ahire M, More P, Jagtap S, Phadatare SD, Patil AB, Jabgunde AM, Sharma GK, Shinde VS, Pardesi K (2013) Phytochemical analysis and free radical scavenging activity of 
medicinal plants Gnidia glauca and Dioscorea bulbifera. PLoS ONE 8(12):e82529

Gill SS, Tuteja N (2010) Reactive oxygen species and antioxidant machinery in abiotic stress tolerance in crop plants. Plant Physiol Biochem 48(12):909-930

Glaszmann J-C (1987) Isozymes and classification of Asian rice varieties. Theor Appl Genet 74(1):21-30

Gonçalves S, Moreira E, Grosso C, Andrade PB, Valentão P, Romano A (2017) Phenolic profile, antioxidant activity and enzyme inhibitory activities of extracts from aromatic plants used in Mediterranean diet. J Food Sci Technol 54(1):219-227

Hamann T (2012) Plant cell wall integrity maintenance as an essential component of biotic stress response mechanisms. Front Plant Sci 3:77

Hammer $\varnothing$, Harper DA, Ryan PD (2001) PAST: paleontological statistics software package for education and data analysis. Palaeontologia electronica 4(1):9

Haq SU, Verma R, Poonia R, Dhingra P, Kothari S, Kachhwaha S (2019) Effect of multiwalled carbon nanotube (MWCNT) on rice (Pusa Basmati 1121): insight into their physiological and biochemical parameters during growth and development. Int J Pure Appl Biosci 7(2):423-433

Hasanuzzaman M, Nahar K, Alam M, Roychowdhury R, Fujita M (2013) Physiological, biochemical, and molecular mechanisms of heat stress tolerance in plants. Int J Mol Sci 14(5):9643-9684

Hiraga S, Yamamoto K, Ito H, Sasaki K, Matsui H, Honma M, Nagamura Y, Sasaki T, Ohashi Y (2000) Diverse expression profiles of 21 rice peroxidase genes. FEBS Lett 471(2-3):245-250

Hiraga S, Sasaki K, Ito H, Ohashi Y, Matsui H (2001) A large family of class III plant peroxidases. Plant Cell Physiol 42(5):462-468

Hossain MA, Bhattacharjee S, Armin SM, Qian P, Xin W, Li HY, Burritt DJ, Fujita M, Tran LS (2015) Hydrogen peroxide priming modulates abiotic oxidative stress tolerance: insights from ROS detoxification and scavenging. Front Plant Sci 6:420

Hu C, Shi J, Quan S, Cui B, Kleessen S, Nikoloski Z, Tohge T, Alexander D, Guo L, Lin H, Wang J (2014) Metabolic variation between japonica and indica rice cultivars as revealed by non-targeted metabolomics. Sci Rep 4:5067

Hu L, Yang Y, Jiang L, Liu S (2016) The catalase gene family in cucumber: genome-wide identification and organization. Genet Mol Biol 39(3):408-415

Huang M, Guo Z (2005) Responses of antioxidative system to chilling stress in two rice cultivars differing in sensitivity. Biol Plant 49(1):81-84

Hussain HA, Hussain S, Khaliq A, Ashraf U, Anjum SA, Men S, Wang L (2018) Chilling and drought stresses in crop plants: implications, cross talk, and potential management opportunities. Front Plant Sci 9:393

Huyut Z, Beydemir Ş, Gülçin İ (2017) Antioxidant and antiradical properties of selected flavonoids and phenolic compounds. Biochem Res Int 2017:10

Jha Y, Subramanian R (2013) Paddy plants inoculated with PGPR show better growth physiology and nutrient content under saline condition. Chil J Agric Res 73(3):213-219

Kaur N, Dhawan M, Sharma I, Pati PK (2016) Interdependency of reactive oxygen species generating and scavenging system in salt sensitive and salt tolerant cultivars of rice. BMC Plant Biol 16(1):131

Kawakami S-I, Ebana K, Nishikawa T, Sato Y-I, Vaughan DA, Kadowaki K-I (2007) Genetic variation in the chloroplast genome suggests multiple domestication of cultivated Asian rice (Oryza sativa $\mathrm{L}$.). Genome 50(2):180-187

Klotz KL, Liu T-TY, Liu L, Lagrimini LM (1998) Expression of the tobacco anionic peroxidase gene is tissue-specific and developmentally regulated. Plant Mol Biol 36(4):509-520

Korte SM, Koolhaas JM, Wingfield JC, McEwen BS (2005) The Darwinian concept of stress: benefits of allostasis and costs of allostatic load and the trade-offs in health and disease. Neurosci Biobehav Rev 29(1):3-38

Kusano M, Yang Z, Okazaki Y, Nakabayashi R, Fukushima A, Saito K (2015) Using metabolomic approaches to explore chemical diversity in rice. Mol Plant 8(1):58-67

Kwon SI, Lee H, An CS (2007) Differential expression of three catalase genes in the small radish (Rhaphanus sativus L. var. sativus). Mol Cells (Springer Science and Business Media BV) 24(1):37-44

Lotfi N, Vahdati K, Hassani D, Kholdebarin B, Amiri R (2009) Peroxidase, guaiacol peroxidase and ascorbate peroxidase activity accumulation in leaves and roots of walnut trees in response to drought stress. In: VI international walnut symposium, vol 861, pp 309-316

Lu B-R, Cai X, Xin J (2009) Efficient indica and japonica rice identification based on the InDel molecular method: its implication in rice breeding and evolutionary research. Prog Nat Sci 19(10):1241-1252

Mhamdi A, Van Breusegem F (2018) Reactive oxygen species in plant development. Development 145(15):dev164376

Mhamdi A, Queval G, Chaouch S, Vanderauwera S, Van Breusegem F, Noctor G (2010) Catalase function in plants: a focus on Arabidopsis mutants as stress-mimic models. J Exp Bot 61(15):4197-4220

Mittler R (2002) Oxidative stress, antioxidants and stress tolerance. Trends Plant Sci 7(9):405-410

Mittler R (2017) ROS are good. Trends Plant Sci 22(1):11-19

Moongngarm A, Saetung N (2010) Comparison of chemical compositions and bioactive compounds of germinated rough rice and brown rice. Food Chem 122(3):782-788

Nadir S, Khan S, Zhu Q, Henry D, Wei L, Lee DS, Chen L (2018) An overview on reproductive isolation in Oryza sativa complex. AoB Plants 10(6):ply060

Niu L, Liao W (2016) Hydrogen peroxide signaling in plant development and abiotic responses: crosstalk with nitric oxide and calcium. Front Plant Sci 7:230

Oka H (1988) Indica-Japonica differentiation of rice cultivars. Origin Cultiv Rice 141:179

Panda D, Mandal L, Barik J, Mishra SS, Padhan B (2019) Improvement of growth, photosynthesis and antioxidant defense in rice (Oryza sativa L.) grown in fly ash-amended soil. Proc Natl Acad Sci India Sect B Biol Sci 89(3):853-860

Pandey V, Awasthi M, Singh S, Tiwari S, Dwivedi U (2017) A comprehensive review on function and application of plant peroxidases. Biochem Anal Biochem 6(308):1-16

Passardi F, Longet D, Penel C, Dunand C (2004) The class III peroxidase multigenic family in rice and its evolution in land plants. Phytochem 65(13):1879-1893

Petrov VD, Van Breusegem F (2012) Hydrogen peroxide-a central hub for information flow in plant cells. AoB Plants 2012:pls014

Poli Y, Nallamothu V, Balakrishnan D, Ramesh P, Desiraju S, Mangrauthia SK, Voleti SR, Neelamraju S (2018) Increased catalase activity and maintenance of Photosystem II distinguishes highyield mutants from low-yield mutants of rice var. Nagina22 under low-phosphorus stress. Front Plant Sci 9:1543

Prasad G, Prasadarao U, Rani NS, Rao L, Pasalu I, Muralidharan K (2001) Indian rice varieties released in countries around the world. Curr Sci 80(12):1508-1511

Ribeiro B, Rangel J, Valentão P, Baptista P, Seabra RM, Andrade PB (2006) Contents of carboxylic acids and two phenolics and antioxidant activity of dried Portuguese wild edible mushrooms. J Agric Food Chem 54(22):8530-8537

Romero LM (2004) Physiological stress in ecology: lessons from biomedical research. Trends Ecol Evol 19(5):249-255

Rossatto T, do Amaral MN, Benitez LC, Vighi IL, Braga EJ, de Magalhaes Júnior AM, Maia MA, da Silva Pinto L (2017) Gene expression and activity of antioxidant enzymes in rice plants, cv. BRS AG, under saline stress. Physiol Mol Biol Plants 23(4):865-875 
Sarkar RK, Mahata KR, Singh DP (2013) Differential responses of antioxidant system and photosynthetic characteristics in four rice cultivars differing in sensitivity to sodium chloride stress. Acta Physiol Plant 35(10):2915-2926

Scandalios J (2005) Oxidative stress: molecular perception and transduction of signals triggering antioxidant gene defenses. Braz $\mathbf{J}$ Med Biol Res 38(7):995-1014

Schrader M, Fahimi HD (2006) Peroxisomes and oxidative stress. BBA Mol Cell Res 1763(12):1755-1766

Sharma P, Dubey RS (2005) Drought induces oxidative stress and enhances the activities of antioxidant enzymes in growing rice seedlings. Plant Growth Regul 46(3):209-221

Sharma P, Dubey R (2007) Involvement of oxidative stress and role of antioxidative defense system in growing rice seedlings exposed to toxic concentrations of aluminum. Plant Cell Rep 26(11):2027-2038

Sharma P, Jha AB, Dubey RS, Pessarakli M (2012) Reactive oxygen species, oxidative damage, and antioxidative defense mechanism in plants under stressful conditions. J Bot 2012:26

Sharma I, Ching E, Saini S, Bhardwaj R, Pati PK (2013) Exogenous application of brassinosteroid offers tolerance to salinity by altering stress responses in rice variety Pusa Basmati-1. Plant Physiol Biochem 69:17-26

Sharma S, Kumar R, Sahoo PK, Mittal S (2020) Geochemical relationship and translocation mechanism of arsenic in rice plants: a case study from health prone south west Punjab, India. Groundw Sustain Dev 10:100333

Singh S, Verma A, Dubey VK (2012) Effectivity of anti-oxidative enzymatic system on diminishing the oxidative stress induced by aluminium in chickpea (Cicer arietinum $\mathrm{L}$.) seedlings. Braz $\mathrm{J}$ Plant Physiol 24(1):47-54

Sompong R, Siebenhandl-Ehn S, Linsberger-Martin G, Berghofer E (2011) Physicochemical and antioxidative properties of red and black rice varieties from Thailand, China and Sri Lanka. Food Chem 124(1):132-140

Sutharut J, Sudarat J (2012) Total anthocyanin content and antioxidant activity of germinated colored rice. Int Food Res J 19(1):215-221

Taggar GK, Gill RS, Gupta AK, Sandhu JS (2012) Fluctuations in peroxidase and catalase activities of resistant and susceptible black gram (Vigna mungo (L.) Hepper) genotypes elicited by Bemisia tabaci (Gennadius) feeding. Plant Signal Behav 7(10):1321-1329

Tian S, Nakamura K, Kayahara H (2004) Analysis of phenolic compounds in white rice, brown rice, and germinated brown rice. $\mathrm{J}$ Agric Food Chem 52(15):4808-4813

Tripathi KK WR, Govila OP, Ahuja V (2011) Biology of Oryza Sativa L. (rice). India: Series of Crop Specifc Biology Documents. Ministry of Science and Technology, India
Tsukagoshi H (2016) Control of root growth and development by reactive oxygen species. Curr Opin Plant Biol 29:57-63

Umnajkitikorn K, Faiyue B, Saengnil K (2013) Enhancing antioxidant properties of germinated Thai rice (Oryza sativa L.) cv. Kum Doi Saket with salinity. Rice Res. https://doi.org/10.4172/23754338.1000103(Open Access)

Vaughan DA, Morishima H, Kadowaki K (2003) Diversity in the Oryza genus. Curr Opin Plant Biol 6(2):139-146

Vichapong J, Sookserm M, Srijesdaruk V, Swatsitang P, Srijaranai S (2010) High performance liquid chromatographic analysis of phenolic compounds and their antioxidant activities in rice varieties. LWT Food Sci Technol 43(9):1325-1330

Walton P, Pizzitelli M (2012) Effects of peroxisomal catalase inhibition on mitochondrial function. Front Physiol 3(108):1-10

Wang R-J, Hu M-L (2011) Antioxidant capacities of fruit extracts of five mulberry genotypes with different assays and principle components analysis. Int J Food Prop 14(1):1-8

Wang Z, Second G, Tanksley S (1992) Polymorphism and phylogenetic relationships among species in the genus Oryza as determined by analysis of nuclear RFLPs. Theor Appl Genet 83(5):565-581

Wang J, Zhong X, Zhu K, Lv J, Lv X, Li F, Shi Z (2018) Reactive oxygen species, antioxidant enzyme activity, and gene expression patterns in a pair of nearly isogenic lines of nicosulfuronexposed waxy maize (Zea mays L.). Environ Sci Pollut Res 25(19): 19012-19027

Welinder KG (1992) Superfamily of plant, fungal and bacterial peroxidases. Curr Opin Struct Biol 2(3):388-393

Wong SP, Leong LP, Koh JHW (2006) Antioxidant activities of aqueous extracts of selected plants. Food Chem 99(4):775-783

Wu C, Ding X, Ding Z, Tie W, Yan Y, Wang Y, Yang H, Hu W (2019) The Class III peroxidase (POD) gene family in cassava: identification, phylogeny, duplication, and expression. Intl J Mol Sci 20(11):2730

Xie X, He Z, Chen N, Tang Z, Wang Q, Cai Y (2019) The roles of environmental factors in regulation of oxidative stress in plant. BioMed Res Int 2019:11

Yamane K, Mitsuya S, Kawasaki M, Taniguchi M, Miyake H (2009) Antioxidant capacity and damages caused by salinity stress in apical and basal regions of rice leaf. Plant Prod Sci 12(3):319-326

Yang Y, Zhu K, Xia H, Chen L, Chen K (2014) Comparative proteomic analysis of indica and japonica rice varieties. Genet Mol Biol 37(4):652-661

Zhang Y-K, Zhu D-F, Zhang Y-P, Chen H-Z, Xiang J, Lin X-Q (2015) Low $\mathrm{pH}$-induced changes of antioxidant enzyme and ATPase activities in the roots of rice (Oryza sativa L.) seedlings. PLoS ONE 10(2):e0116971 